\title{
Subjective Well-Being and Income Below the 'At-Risk-of-Poverty Threshold': Analysis of Slovak EU-SILC Data
}

\author{
Jozef Džuka, Martin Lačný, Peter Babinčák \\ University of Prešov, Faculty of Arts, 17. Novembra 1, 08001 Prešov, Slovak Republic
}

\begin{abstract}
The objective of the present research was to examine the relationship of income below the 'atrisk-of-poverty threshold' and well-being variables among selected groups of Slovak citizens based on the analysis of secondary data. Responses of 7851 Slovaks selected from the EU-SILC 2013 data $(N=13286)$ were analyzed. The participants were selected on the basis of self-defined current economic status as follows: employees working full-time $(n=5156)$, the unemployed $(n=845)$, retirees $(n=1850)$. The stepwise multiple regression revealed that the relationship of income to well-being variables in each of these three groups was different. The differentiated income effect in relation to well-being variables depending on selfdefined economic status and study limitations were discussed.
\end{abstract}

Key words: poverty, subjective well-being, EU-SILC 2013 data, at-risk-of-poverty threshold

\section{Introduction}

The European Union - Statistics on Income and Living Conditions (EU-SILC) is the most relevant household survey at the European level in the field of household income, living standards and poverty. In 2004 the Slovak Republic became a member of the European Union and since 2005 the Statistical Office of the Slovak Republic has carried out a sample survey on the income and living conditions of households in Slovakia. In 2013 a new instru-

\section{Acknowledgments \\ This work was supported by the Agency for Re- search and Development under contract No. APVV- 15-0404.}

Correspondence concerning this article should be addressed to Dr. Martin Lačný, University of Prešov, Faculty of Arts, 17. Novembra 1,08001 Prešov, Slovak Republic. E-mail: martin.lacny@unipo.sk

Received November 8, 2018 ment, the EU-SILC ad-hoc module for measuring subjective well-being (EU-SILC 2013 Module On Well-Being) was administered for the first time. The inclusion of this module was also perceived in the sense that the data obtained would represent an important potential for researchers to engage in an in-depth analysis (De Smedt, 2013). Using data collected in 2012 among individuals over 16 years old living in Slovakia $(N=13286)$ based on the EUSILC 2013 sample statistical survey, the present paper aims to analyze the relationship of income poverty in three groups of the Slovak population - employees working full-time, the unemployed, and retirees - to psychological variables detected with the Module On Well-Being. In particular, the paper analyzes whether the differences in income below and above the 'at-risk-of-poverty threshold' explain subjective well-being of these three groups. In the year under review, $12.8 \%$ of the Slovak population (about 695 thousand persons) had income below the 'at-risk-of-poverty threshold' (Vlačuha \& Kováčová, 2014). 


\section{Definition of Basic Concepts and an Overview of Earlier Research}

\section{Income Poverty}

Poverty as one of the two key variables in the paper was delimited on the basis of a monetary approach, which identifies poverty as a shortfall in consumption or income from some poverty line. As Annoni and WeziakBialowolska (2016, p. 183) state, "the perfect measure of poverty in terms of economic wellbeing should be a combination of income, consumption and welfare. Although the measurement of income is not a problematic issue, at least to some extent, the measurement of consumption level and welfare is not straightforward. For these reasons, the level of disposable income is often used as a proxy of consumption". This kind of relative measure is the EU-SILC income poverty threshold that sets the relative risk-of-poverty line at $60 \%$ of the national median equivalized disposable income. ${ }^{1}$ Thus, this approach is not always applied equally in research analyses. For example, Nygård, Härtull, Wentjärvi and Jungerstam
(2017) describe income poverty as "objective poverty", and in their analysis of secondary data (the 2010 GERDA Survey) they identify it as a dichotomized variable constructed on the basis of one question in which people did not assess their net income but gross monthly income. Three other well-known approaches to the definition of poverty (see Laderchi, Saith, $\&$ Stewart, 2003) put an emphasis on its different aspects. Participatory Poverty Assessment $(\mathrm{PPA})^{2}$ uses a person's subjective decision about what it means to be poor and the extent to which they perceive to be poor. The capability approach considers that person to be poor whose freedom or chances to materialize his/her own lifestyle (Arndt \& Volkert, 2007) are limited. The fourth approach to poverty is known as a social exclusion approach, in which an emphasis is placed on social rather than individual perspective, and poverty is defined as a person's membership in particular groups of people (the aged, disabled, ethnic minority). In industrialized societies they are generally the unemployed, people with poor access to housing or people with very low income. The four approaches to the definition of poverty are one-dimensional. Several economists

\footnotetext{
${ }^{1}$ For poverty indicators, the equivalized disposable income is calculated from the total disposable income of each household divided by the equivalized household size. In order to reflect differences in a household's size and composition, the total net household income (income from work, investment and social benefits, plus any other household income after tax and other deductions), that is available for spending or saving, is divided by the number of 'equivalent adults', using the so-called modified OECD equivalence scale. The scale gives a weight to all members of the household (1.0 to the first adult; 0.5 to the second and each subsequent person aged 14 and over; 0.3 to each child aged under 14) and then adds these up to arrive at the equivalized household size. Finally, the resulting equivalized disposable income is attributed equally to each member of the household. In case of the EU-SILC data the income reference period is a fixed 12-month period (such as the previous calendar or tax year) for all countries except UK for which the income reference period is the current year and Ireland for which the survey is continuous and income is collected for the last twelve months (Eurostat, 2018).

${ }^{2}$ Participatory Poverty Assessment (PPA) as an approach to poverty measurement takes account of the attitudes of poor people in the analysis of poverty and in the formulation of poverty reduction strategies through public policy instruments. The methodological specificity of recent PPA approaches lies in the fact that researchers do not seek to prioritize the criteria on the basis of which poverty is assessed. They focus mainly on the perception of respondents about their well-being. Benefits of a participatory approach lie primarily in identifying the hidden dimensions of poverty and in the possibilities of analysis of causality and processes that make people become poor or lose poverty (Norton et al., 2001).
} 
have suggested multidimensional approaches, which have brought about several indices such as Human Development Index (HDI), Physical Quality of Life Index (PQLI) or Multidimensional Poverty Index (MPI). For example, MPI is a global multidimensional poverty index (Alkire et al., 2015), which includes 10 indicators grouped into three dimensions - education, health, and living standard. In the present paper, the income approach is used and, in accordance with the EU-SILC 2013 definition, the object of interest are the people below the 'at-risk-of-poverty threshold', i.e. persons whose income was less than $60 \%$ of the median of the national equivalized disposable income per household assigned to individuals.

\section{Well-Being Correlates}

The analyzed psychological variables represent, in contrast with income poverty (real income level), subjectively assessed attributes of a person's own experiencing. The choice of psychological variables was limited by the variables identified by the EU-SILC 2013 Module On Well-Being. Specifically, these are the three subjectively assessed psychological aspects of experiencing for which we have used the terms overall life satisfaction, mean score of satisfaction with three aspects of life, and affect. The variables bearing these names are considered by subjective well-being (SWB) researchers as basic components of SWB. For example, Diener (2000, p. 34) defines subjective well-being as follows: "Thus, there are a number of separable components of SWB: life satisfaction (global judgments of one's life), satisfaction with important domains (e.g., work satisfaction), positive affect (experiencing many pleasant emotions and moods), and low levels of negative affect (experiencing few unpleasant emotions and moods". The psychological variables identified by the EU-SILC
2013 Module On Well-Being are not identical with the SWB construct but they can be considered to be an approximation of the SWB concept quoted above. This is not a case of sameness but of approximation because, despite a considerable degree of content similarity between the constructs, their operationalization and the way they are measured in the EU-SILC 2013 are different. While the EU-SILC 2013 uses a single self-report item to measure each construct, "Recent measures of SWB, however, contain multiple items" (Diener, 2000, p. 35). For the sake of a higher approximation, items of the EU-SILC 2013 Module on WellBeing concerning satisfaction with important domains and affect were integrated into the scales. Another frequent concept in the field of income and psychological variables research is quality of life (QoL). It is not unusual for SWB and QoL to be interchanged or used as if they were equivalent alternatives. For example, Smith, Sim, Scharf, and Phillipson (2004) state in the objectives of their work: "While the focus of the article is on the determinants of quality of life among older people who live in a particular type of geographic location, the analysis raises several broader issues for research on wellbeing in later life" (p. 794). It may be added that other psychological variables are examined only rarely. One exception to this is, for example, Haushofer's (2013) publication which highlights the fact that, while among researchers there has been a growing interest in the research on the relationship of income levels to happiness and life satisfaction, the relationship of income to other psychological consequences is rarely studied. His analysis was concerned with the effect of income poverty on locus of control, intrinsic motivation, trust, prosocial attitudes, feelings of meaninglessness, and risk-taking. These variables were not taken into account in our analysis because the EU-SILC 2013 Module On Well-Being did not detect them. 


\section{Income Poverty and Well-Being Correlates}

Smith et al. (2004) analyzed the quality of life factors among people over the age of 60 and stated that out of thirteen predictors tested using multiple linear regression and sequence regression, the equivalized income (nearly $40 \%$ of the sample had an equivalized weekly income of less than £100) and socio-demographic characteristics of the interviewed did not have relationships to life satisfaction. The strongest predictor of subjectivelife satisfaction(Diener, Emmons, Larsen, \& Griffin, 1985) and in single-item measure of quality of life ("very good - very bad") was the perception ofone's own health. Similarly, Diener, Suh, Lucas, and Smith (1999) stated that external factors, such as various resources and demographic factors, are responsible for only a small part of the variancein SWB. Although we can state that the findings from the viewpoint of methodology, sampling strategies and procedures used to measure the variables are incomparable, the impact of the income on SWB was small or zero. In their recent study, Ngamaba, Panagioti, and Armitage(2017) report the results of their meta-analysis of the relationship between income inequality and SWB. Theyanalyzed 619 publications in total. After removing duplicates and after screening for relevance, they performed a systematic review of 39 studies from which they selected 24 studies for meta-analysis. They came to the conclusion that the association between income inequality (endogenous Gini ${ }^{3}-$ calcu-

\footnotetext{
${ }^{3}$ Income distribution measures the gap between the various strata of the population. In a very uneven income distribution, the rich are very rich and the poor are very poor, comparatively. Gini coefficient is an economic measure of inequality in income distribution. It is calculated from the Lorenz curve, in which cumulative family income is plotted against the number of families arranged from the poorest to the richest. On a scale of 0 to 1 , the lower the Gini coefficient, the more evenly distributed the wealth (Eurostat, 2013b).
}

lated from individuals' responses and exogenous Gini extracted from nation-level data) and SWB (happiness and/or life satisfaction) in developed countries is weak, almost zero and not statistically significant, suggesting thus no association between income inequality and SWB. Apart from research that confirms a weak or missing relationship between income and SWB, other studies indicate theopposite. Asto income inequality and SWB, Yu and Wang (2017, p. 1) explain its existence as follows: “...the Gini coefficient (a common index of a society's income inequality) and its quadratic term were significant predictors of personal happiness." They argue that the existence of a curvilinear relationship between income inequality and happiness is underpinned by psychological processes of jealousy and signal effects (Senik, 2008). Another explanation regarding the existence of the relationship between income and SWB was published by Cummins (2000). He assumes that 1) income does not influence SWB directly: "Income can act on all processes at the second order level to make the maintenance of SWB homeostasis more likely. In terms of the internal buffers, income has the power to directly facilitate each one. Thus, income has a positive relationship with primary control (Lussier et al., 1997), self-esteem(e.g., Carpenter, 1997; Tran et al., 1991), and optimism (e.g., Eckersley, 1997)"(p. 138).2) The second explanation is related to the statistical procedure used, which can mask the income effect. If income effect in relation to SWB is tested using hierarchical regression together with the subjective variable and, in the first step, the subjective and objective variables are inserted into the equation together, theobjective variable effect is low because subjective variables share more variance with other subjective rather than objective variables. As an example, the author concludes that if perceived health was inserted together with income in the first step, then the conclusion about the relationship of both variables to SWB is not correct. Based on his homeostatic theory, Cummins 
(2000) draws two conclusions: people who are poor experience lower SWB; and the relationship between income and SWB is strongest for people who are poor.

\section{Current Study}

The objective of the study was, based on secondary data from the EU-SILC 2013 statistical sample survey, to analyze the relationship of income above and below the poverty line and subjective well-being in three groups of people who have their own income-employees working fulltime, the unemployed and retirees. We assume that in all three groups the income below the 'atrisk-of-poverty threshold' is in a negative relationship to subjective well-being variables.

\section{Method}

Our data which come from theEU-SILC 2013 were obtained on the basis of a written request sent to Eurostat (December 2016). After verifying the registration of the institution as a research entity and after assessing the applicant's research intention, we asked for and received the so-called EU-SILC microdata in .csv format. Before their proper analysis, the .csv data were converted to .sav format (see Mack, 2016). For a detailed description of data sets of this survey see Methodological Guidelines and Description of the EU-SILC Target Variables (Eurostat, 2013a). Even though theEU-SILC project started earlier, we present results from this wave because psychological variables were a part of research for the first time in 2013 (Module On Well-Being).

\section{Participants}

Thevariables wereavailable for $13286 \mathrm{individu-}$ als from Slovakia, which is a nationallyrepresentative sample (the demographics of the total sample is available from the authors). We restricted our analysis, based on self-defined cur- rent economic status, to three groups - employees working full-time, the unemployed and retirees, and, at the same time, only to the never married and married persons (widowed and divorced persons were omitted). Persons who belong to relatively small subgroups or who do not have their own income (pupils, students) were also omitted from the analysis. This procedure left us with a total of 7900 participants. Prior tothe analysis, the variables were checked for the presence of extremevalues (income) and for data completeness. The income variable for 3 people showed extreme (unrealistic) values: 2 persons reported an annual equivalized income of 10.85 Euro and 1 person an income of 41529.90 Euro. The education variable contained 7 missing data, and 39 participants did not provide information about their subjectively assessed health. These 49 persons $(0.6 \%)$ were omitted from the analysis. The analyzed sample consisted of 7851 persons of whom employees working full-time numbered 5156(65.7\%), the unemployed 845(10.7\%), and retirees $1850(23.6 \%)$. Above the 'at-risk-of-poverty threshold' were 7344 (93.5\%) persons and $507(6.5 \%)$ persons were below the 'at-risk-ofpoverty threshold'. Females numbered 3791 (48.3\%) and males 4,060(51.7\%), never married $2224(28.3 \%)$ and married 5627 (71.7\%), lower education (below secondary education inclusive) 5959 (75.9\%) and higher education (above secondary education) 1892 (24.1\%). For descriptives of the analyzed groups see Table 1 .

\section{Variables of Interest}

A list of all identified dimensions, topics and subtopics and all variables of the EU-SILC 2013 Module On Well-Being has been published by, for example, De Smedt (2013).

\section{Equivalized Household Income}

Equivalized household income is the household disposable income for that year (2012) di- 
Table 1 Descriptives for the analyzed groups $(N=7851)$

\begin{tabular}{|c|c|c|c|}
\hline Variable & $\begin{array}{l}\text { Employees } \\
\text { working full-time } \\
\quad(n=5156)\end{array}$ & $\begin{array}{l}\text { Unemployed } \\
\qquad(n=845)\end{array}$ & $\begin{array}{l}\text { Retirees } \\
(n=1850)\end{array}$ \\
\hline \multicolumn{4}{|l|}{ Gender } \\
\hline Female & $2424(47 \%)$ & $426(50.4 \%)$ & $941(50.9 \%)$ \\
\hline Male & $2732(53 \%)$ & $419(49.6 \%)$ & $909(49.1 \%)$ \\
\hline \multicolumn{4}{|l|}{ Age, in years } \\
\hline$M$ & 41.3 & 35.1 & 67.4 \\
\hline$S D$ & 11.1 & 12.5 & 6.65 \\
\hline$M d n$ & 41.0 & 12.54 & 66.0 \\
\hline Range & $18-70$ & $16-63$ & $34-93$ \\
\hline \multicolumn{4}{|l|}{ Marital status } \\
\hline Never married & $1643(31.9 \%)$ & $465(55.0 \%)$ & $116(6.3 \%)$ \\
\hline Married & $3513(68.1 \%)$ & $380(45.0 \%)$ & $1734(93.7 \%)$ \\
\hline \multicolumn{4}{|l|}{ Level of education } \\
\hline Below secondary education inclusive & $3645(70.7 \%)$ & $723(85.6 \%)$ & $1591(86 \%)$ \\
\hline Above secondary education & $1511(29.3 \%)$ & $122(14.4 \%)$ & $259(14 \%)$ \\
\hline \multicolumn{4}{|l|}{ A Person's Income } \\
\hline Above the 'at-risk-of-poverty threshold' & $5004(97.1 \%)$ & $558(66 \%)$ & $1782(96.3 \%)$ \\
\hline Below the 'at-risk-of-poverty threshold' & $152(2.9 \%)$ & $287(34 \%)$ & $68(3.7 \%)$ \\
\hline \multicolumn{4}{|l|}{ Equivalized household income } \\
\hline$M$ & 8884.52 & 5606.05 & 6950.03 \\
\hline$S D$ & 3455.64 & 3101.67 & 2214.37 \\
\hline$M d n$ & 8401.59 & 5432.58 & 6472.74 \\
\hline Range & $334.7-36622.5$ & $107.1-33970.1$ & $1201.7-21109.5$ \\
\hline
\end{tabular}

Notes. Equivalized household income is a household's disposable income for that year (2012) divided by the sum of consumption equivalents of that household using the modified OECD scale to reflect economies of scale.

A person is counted as being below the 'at-risk-of-poverty threshold' in a given year if his or her equivalized household disposable income is less than $60 \%$ of the national median equivalized household income for that year (The 'at-risk-of-poverty threshold' in Slovakia in 2012 was: 7007.88 * $0.6=4204.73$ ).

vided by the sum of consumption equivalents of that household, using the modified OECD scale to reflect economies of the scale: for each household the first adult receives a weight of 1 , each additional adult gets a weight of 0.5 and each (additional) child under 14 years receives a weight of 0.3. For further details of the sources included in household income and the equivalence scale, see Eurostat (2010). It is an indicator, which expresses the calculated net annual income of the person living in a given household, who an- swered the questions from the questionnaire regarding all the variables analyzed in this article.

\section{A Person's Income below the 'At-Risk-of-Pov- erty Threshold'}

A person is counted as being below the 'atrisk-of-poverty threshold' in a given year if his or her equivalized household disposable income is less than $60 \%$ of the national median equivalized household income for that year (in 
2012 the 'at-risk-of-poverty threshold' in Slovakia was: $7007.88 * 0.6=4204.73$ ).

\section{Self-Defined Current Economic Status}

Employees working full-time, the Unemployed and Retirees.

\section{Well-Being Variables}

Items from the EU-SILC 2013 Module On WellBeing were used to create measures of overall life satisfaction (1 Item), mean score of satisfaction with three aspects of life (3 Items) and affect (5 Items).

\section{Overall Life Satisfaction (1 Item)}

"Assess the situation and state how satisfied you are ..." "with your present life" (Use a scale from 0 to 10 where 0 means absolute dissatisfaction and 10 means complete satisfaction). Respondents also had the option to use the "I do not know" response, which also applies to questions about mean score of satisfaction with three aspects of life and affect.

Mean Score of Satisfaction with Three Aspects of Life (3 Items)

The EU-SILC 2013 Module On Well-Being contained eight items related to satisfaction with different areas of life (accommodation, job, commuting time, time use, personal relationships, recreational or green areas, living environment, financial situation) measured by a response scale identical with that for overall life satisfaction. Because satisfaction with financial situation is a subjective assessment of income, this item has not been included among domains of satisfaction because of its possible contamination with objective income. Similarly, job satisfaction and job commuting time were not included among the domains because a part of the sample consisted of persons, who are not employed (unemployed or retired). The remaining three items, i.e. satisfaction with time use, recreational or green areas and living environment do not correspond with the construct of subjective well-being, for which reason they were not included among the domains of satisfaction. Only the following three items were used and grouped into a scale: "Assess the situation and state how satisfied you are ...." "... with your housing", “... with your personal relationships" and "How much do you feel that the things you do in your life are worth doing? (Use a scale from 0 to 10 in which 0 means not worth doing at all and 10 means they are absolutely worth it)". The reliability of this scale of mean score of satisfaction with three aspects of life was alpha $=.71$.

\section{Affect (5 Items)}

Five items that concerned emotional experiencing were analyzed using PCA. Based on a single-factor solution they could be grouped into a scale: "How much time in the last four weeks: “" “.. have you been very nervous?", "have you felt so down that nothing could cheer you up?", “... have you felt calm and balanced?", "have you felt sorry and depressed?" "have you been happy?" These items used a five-point score of 5 to 1: "Never", "Seldom", "Sometimes", "Mostly" and "Always". Before calculating the reliability and adding the score into the scale, the responses were recoded so that the higher value expressed higher frequency of positive experiencing. The reliability of scale alpha $=.83$.

\section{Socio-Demographic Characteristics}

Gender, Age in years, Level of education (below secondary education inclusive, above secondary education), Marital status (Never married, Married). 


\section{Subjective Health Rating}

The EU-SILC 2013 Module On Well-Being included an item that was related to subjective assessment of one's own health using a fivepoint response scale (1 to 5): "How would you assess your overall health? It is: very bad, bad, neither good nor bad, good, very good".

\section{Results}

The Level of Equivalized Household Income among Employees Working Full-Time, the Unemployed, and Retirees

Before analyzing the relationship of income below and above the 'at-risk of poverty threshold' of three groups of Slovak population with the well-being correlates surveyed by means of the Module On Well-Being, we compared these groups in terms of their equivalized household income. One-way ANOVA was used with the three-level group factor of self-defined current economic status for employees working fulltime, the unemployed, retirees and the dependent variable of equivalized household income. The analysis was performed using IBM SPSS One-way ANOVA. Prior to the analysis, the dependent variable income was checked for completeness - there were no missing data. The assumption of normal distributions of the dependent variable in the entire sample was violated, skew $=1.62$. In order to improve the normality of income distribution, we transformed the variable with the help of sqrt-transformation so that the skew was $=.41$ and within each group $<1$. The assumption of homogeneity of variances was violated (Levene's test was significant) and group sizes were different. Therefore, the Robust Test of Equality of Means (Welch) and the Games-Howell post hoc test were used. The differences between groups were statistically highly significant $(F(2,2081.67)=$
$623.64, p<.001)$. Games-Howell post hoc tests revealed statistically significant differences between all three groups. The lowest income was identified among the unemployed $(M=$ 5606.05 Euro), which was followed by retirees $(M=6950.03$ Euro) and the highest income was detected in the category of employees working full-time (8884.52 Euro).

Income below and above the 'At-Risk-of-Poverty Threshold' and Well-Being Correlates

Prior to the analysis, the dependent variables of overall life satisfaction, mean score of satisfaction with three aspects of life, and affect were checked for completeness of data. Two kinds of missing data were identified: system data with a relatively low number $(n=66,0.8 \%)$ and also data representing the "I do not know" responses. This type of missing data could not be replaced; in both cases the missing data were eliminated by excluding people from the analysis (a listwise method). Therefore, the number of persons analyzed was lower than the total number of persons in each group and varied depending on the dependent variable analyzed.

\section{Regression Analysis}

For each group-employees working full-time, the unemployed and retirees, sequential regression was calculated separately. The predictors income below and above the 'at-risk-of-poverty threshold' as dummyvariables, gender, age, education, marital status and subjectively assessed health - were added in blocks and their relationship to the criterion was tested statistically using the stepwise method. "The regression is sequential over blocks, but statistical within blocks" (Tabachnick \& Fidell, 2013,p. 140). When building blocks, we used Cummins' (2000) opinion that subjective variables share more variance with other subjective variables. Therefore, in the first block, income was entered stepwise, socio-de- 
mographic characteristics of the individuals were entered stepwise in the second block, and subjective health ratings were entered stepwise in the thirdblock. In all threegroups, the dependent variables-overall life satisfaction, mean score of satisfaction with threeaspects oflife, and affect were normally distributed; multicolinearity was controlled(Tolerance value $>1-R^{2}$, Leech, Barrett, \& Morgan, 2015); in each of the groupsrepresented by codes on the dummy variables there was a sufficient number of scores ( $n>50$, Warner, 2008). The analysis was performed using IBM SPSS Regression.
Table 2 shows the correlations between dependent variables and predictors for three groups separately. ${ }^{4}$ Income below the 'at-riskof-poverty threshold' correlates negatively with all three correlates of well-being. In the case of the unemployed, the correlations are highly significant and higher than .14; among the employees working full-time and retirees correlations are low; in the case of the mean score of satisfaction with three aspects of life they are insignificant and in the case of total life satisfaction and affect they are significant but lower than .07 .

Table 2 Bivariate correlations (Spearman's rho) between dependent variables and predictors for each group separately

\begin{tabular}{|c|c|c|c|c|c|c|c|}
\hline Dependent variables & $n$ & Income & Gender & Age & Education & MStatus & Health \\
\hline \multicolumn{8}{|c|}{ Employees working full-time $(n=5156)$} \\
\hline Overall life satisfaction & 4935 & $-.07 * *$ & .02 & $-.13 * *$ & $.18 * *$ & .02 & $.25 * *$ \\
\hline $\begin{array}{l}\text { Mean score of satisfaction } \\
\text { with three aspects of life }\end{array}$ & 4375 & -.02 & .02 & $.05 * *$ & $.09 * *$ & $-.13 * *$ & $.14 * *$ \\
\hline Affect & 4588 & $-.04 * *$ & -.02 & $-.13 * *$ & $.08 * *$ & $.06 * *$ & $.26 * *$ \\
\hline \multicolumn{8}{|c|}{ Unemployed $(n=845)$} \\
\hline Overall life satisfaction & 775 & $-.23 * *$ & $.17 * *$ & $-.11 * *$ & $.14^{* *}$ & -.00 & $.21 * *$ \\
\hline $\begin{array}{l}\text { Mean score of satisfaction } \\
\text { with three aspects of life }\end{array}$ & 633 & $-.27 * *$ & $.17^{* *}$ & .01 & $.12 * *$ & $-.15 * *$ & $.14^{* *}$ \\
\hline Affect & 713 & $-.14 * *$ & $.14 * *$ & $-.22 * *$ & $.08^{*}$ & $.08^{*}$ & $.28 * *$ \\
\hline \multicolumn{8}{|c|}{ Retirees $(n=1850)$} \\
\hline Overall life satisfaction & 1755 & $-.05 *$ & .03 & $-.07 * *$ & $.07 * *$ & -.04 & $.37 * *$ \\
\hline $\begin{array}{l}\text { Mean score of satisfaction } \\
\text { with three aspects of life }\end{array}$ & 1476 & -.02 & -.01 & -.04 & .02 & $-.06^{*}$ & $.23^{* *}$ \\
\hline Affect & 1593 & $-.05 *$ & .01 & -.04 & $.05^{*}$ & -.03 & $.33 * *$ \\
\hline
\end{tabular}

Notes. Overall life satisfaction, and Mean score of satisfaction with three aspects of life range from 0 to 10, Affect and Subjective health ratings range from 1 ("very bad") to 5 ("very good"), with a high value indicating strong endorsement of the construct. For Income below the "at-risk-ofpoverty threshold' 1 signifies "yes" and 0 "no", for Gender, 1 signifies "female" and 0 "male." Age is given in years. For Education, 1 signifies "high", 0 "low", for Marital status 1 signifies "married" and 0 "never married".

$* p<.05 ; * * p<.01$

\footnotetext{
${ }^{4}$ On the reviewer's suggestion regarding the different sample sizes used for dependent variables, we have tested differences in bivariate correlations between dependent variables and predictors for each group after excluding people with missing values across whole sample. Differences between correlation coefficients were marginal and non-significant.
} 


\section{Employees Working Full-Time}

Sequential regression was used to determine if income improves the prediction of three wellbeing variables in the group of employees working full-time separately. The dummy variables for income below and above the 'at-risk-of-poverty threshold' were entered stepwise in the first block. The three dummy variables, i.e. gender, education, marital status, were entered stepwise in the second block together with age; subjectively assessed health state was entered stepwise in the third block. Table 3 presents $R$, $R$-squared change, the unstandardized regression coefficients $(B)$ and intercept, after entering all predictors in three blocks for the group of employees working full-time. The table contains only significant predictors.
The stepwise multiple regression analysis with overall life satisfaction as a criterion revealed that income below the 'at-risk-of-poverty threshold' explained $1 \%$ of the variance, higher education explained $3 \%$ of the variance, and better subjectively rated health explained an additional $5 \%$ of the variance in the final step.

A comparable stepwise multiple regression analysis with mean score of satisfaction with three aspects of life and affect as criteria, revealed that income was not a significant predictor and other predictors tested explained a low percentage of variance: marital status $2 \%$ and education $3 \%$ of variance, mean score of satisfaction with three aspects of life and education $1 \%$ and health $6 \%$ of variance. This pattern of results suggests that the variability of the well-being variables in case of employees

Table 3 Regression models for income, gender, age, education, marital status, and health as predictors of overall life satisfaction, mean score of satisfaction with three aspects of life, and affect in group of employees working full-time (accepted models; $p<.05$ )

\begin{tabular}{|c|c|c|c|c|c|}
\hline Predictors & $R$ & $R^{2}$-change & $B$ & $t$ & $p$ \\
\hline \multicolumn{6}{|c|}{ Overall life satisfaction $\left(F_{\text {total }}(3,4931)=166.800 ; p<.000\right)$} \\
\hline Income below & .09 & $.01 * * *$ & -.78 & -5.196 & .000 \\
\hline Education & .20 & $.03 * * *$ & 61 & 10.761 & .000 \\
\hline Health & .30 & $.05 * * *$ & .64 & 17.019 & .000 \\
\hline (Constant) & & & 4.722 & & \\
\hline \multicolumn{6}{|c|}{ Mean score of satisfaction with three aspects of life $\left(F_{\text {total }}(2,4374)=116.661 ; p<.000\right)$} \\
\hline Marital status & .14 & $.02 * * *$ & -.59 & -12.379 & .000 \\
\hline Health & .23 & $.03 * * *$ & .39 & 11.902 & .000 \\
\hline (Constant) & & & 6.488 & & \\
\hline \multicolumn{6}{|c|}{ Affect $\left(F_{\text {total }}(2,4585)=176.243 ; p<.000\right)$} \\
\hline Education & .08 & $.01 * * *$ & .07 & 3.577 & .000 \\
\hline Health & .27 & $.06^{* * *}$ & .22 & 17.836 & .000 \\
\hline (Constant) & & & 3.032 & & \\
\hline
\end{tabular}

Note. Overall life satisfaction, and Mean score of satisfaction with three aspects of life range from 0 to 10, Affect and Subjective health ratings range from 1 ("very bad") to 5 ("very good"), with a high value indicating strong endorsement of the construct. For Income below the "at-riskof-poverty threshold' 1 signifies "yes" and 0 "no". For Education, 1 signifies "high", 0 "low", and for Marital status, 1 signifies "married" and 0 "never married."

$* * * p<.001$ 
working full-time is predicted by income only marginally. Note: equivalized disposable income among employees working full-time, who were below the 'at-risk-of-poverty threshold', was almost three times lower than the income of fulltime employees, who were above the risk of poverty: 3267.09 Euro vs. 9055.15 Euro.

\section{The Unemployed}

The stepwise multiple regression analysis in the group of the unemployed (Table 4) with overall life satisfaction as a criterion revealed that income explained $5 \%$, gender $2 \%$ of the variance, and better subjectively rated health explained additional $4 \%$ of the variance in the final step. Regression analysis of the mean score of satisfaction with three aspects of life as a criterion revealed that income explained $8 \%$, gender $2 \%$ and health $2 \%$ of the variance. Affect as a criterion was predicted with the same three predictors: income below the 'atrisk-of-poverty threshold' explained $2 \%$, gender $1 \%$ and better subjectively rated health explained an additional $10 \%$ of the variance in the final step. These results suggest that the variability of the well-being variables among the unemployed is predicted significantly by income. Note: equivalized disposable income of the unemployed below the 'at-risk-of-poverty threshold' was also almost three times lower than the income of the unemployed above the risk of poverty: 2594.17 Euro vs. 7155.17 Euro.

Table 4 Regression models for income, gender, age, education, marital status, and health as predictors of overall life satisfaction, mean score of satisfaction with three aspects of life, and affect in group of the unemployed (accepted models; $p<.05$ )

\begin{tabular}{|c|c|c|c|c|c|}
\hline Predictors & $R$ & $R^{2}$-change & $B$ & $t$ & $p$ \\
\hline \multicolumn{6}{|c|}{ Overall life satisfaction $\left(F_{\text {total }}(3,771)=32.651 ; p<.000\right)$} \\
\hline Income below & .23 & $.05 * * *$ & -1.01 & -5.704 & .000 \\
\hline Gender & .27 & $.02 * * *$ & .83 & 4.932 & .000 \\
\hline Health & .34 & $.04 * * *$ & .60 & 5.951 & .000 \\
\hline (Constant) & \multicolumn{5}{|c|}{2.863} \\
\hline \multicolumn{6}{|c|}{ Mean score of satisfaction with three aspects of life $\left(F_{\text {total }}(3,629)=28.196 ; p<.000\right)$} \\
\hline Income below & .28 & $.08 * * *$ & -1.02 & -6.880 & .000 \\
\hline Gender & .32 & $.02 * * *$ & .60 & 4.287 & .000 \\
\hline Health & .34 & $.02 * * *$ & .31 & 3.691 & .000 \\
\hline (Constant) & & & 5.669 & & \\
\hline \multicolumn{6}{|c|}{ Affect $\left(F_{\text {total }}(3,709)=35.319 ; p<.000\right)$} \\
\hline Income below & .13 & $.02 * * *$ & -.13 & -2.381 & .018 \\
\hline Gender & .18 & $.01 * * *$ & .25 & 4.659 & .000 \\
\hline Health & .36 & $.10 * * *$ & .30 & 8.986 & .000 \\
\hline (Constant) & & & 2.216 & & \\
\hline
\end{tabular}

Note. Overall life satisfaction, and Mean score of satisfaction with three aspects of life range from 0 to 10, Affect and Subjective health ratings range from 1 ("very bad") to 5 ("very good"), with a high value indicating strong endorsement of the construct. For Income below the "at-riskof-poverty threshold", 1 signifies "yes" and 0 "no". For Gender, 1 signifies "female" and 0 "male".

$* * * p<.001$ 


\section{Retirees}

The stepwise multiple regression analysis in the group of retirees (Table 5) revealed that income did not have a significant relationship to any of the three variables of well-being. Subjectively rated health explained $15 \%$ of overall life satisfaction, $6 \%$ of the mean score of satisfaction with three aspects of life and $13 \%$ of affect. Marital status had a marginal relationship to the mean score of satisfaction with three aspects of life ( $1 \%$ variance). This pattern of results suggests that the variability of well-being variables in case of retirees is predicted completely differently from the other two groups. Of the tested variables, only health appears to be a factor of well-being variables among retirees. Note: equivalized disposable income of retirees below the 'at-risk-of-poverty threshold' was twice as low as the income of retirees above the risk of poverty: 3401.95 Euro vs. 7085.42 Euro.

\section{Discussion}

In terms of equivalized person's disposable income, the three groups, employees working full-time, the unemployed and retirees, were statistically significantly different: the lowest income was that of the unemployed ( $M=$ 5606.05 Euro), which was followed by the income of retirees $(M=6950.03$ Euro) and by the income of the employed (8884.52 Euro), which was the highest. The stepwise multiple regression revealed that the relationship of income to well-being variables in each of these three groups was different. In the group of employees, income was related only to overall life satisfaction; employees with an income below the 'at-risk-of-poverty threshold' had a lower score, but this relationship was weak. Of the three significant predictors within the group of the unemployed, income below the 'at-risk-of-poverty threshold' had the greatest effect on two psychological variables - the

Table 5 Regression models for income, gender, age, education, marital status, and health as predictors of overall life satisfaction, mean score of satisfaction with three aspects of life, and affect in group of retirees (accepted models; $p<.05$ )

\begin{tabular}{|c|c|c|c|c|c|}
\hline Predictors & $R$ & $R^{2}$-change & $B$ & $t$ & $p$ \\
\hline \multicolumn{6}{|c|}{ Overall life satisfaction $\left(F_{\text {total }}(1,1753)=316.315 ; p<.000\right)$} \\
\hline $\begin{array}{l}\text { Health } \\
\text { (Constant) }\end{array}$ & .39 & $.15 * * *$ & $\begin{array}{l}.96 \\
3.999\end{array}$ & 17.785 & .000 \\
\hline \multicolumn{6}{|c|}{ Mean score of satisfaction with three aspects of life $\left(F_{\text {total }}(2,1473)=47.785 ; p<.000\right)$} \\
\hline $\begin{array}{l}\text { Marital status } \\
\text { Health } \\
\text { (Constant) }\end{array}$ & $\begin{array}{l}.08 \\
.25\end{array}$ & $\begin{array}{l}.01 * * \\
.06 * * *\end{array}$ & $\begin{array}{l}-.42 \\
.39 \\
6.906 \\
\end{array}$ & $\begin{array}{r}-2.896 \\
9.278\end{array}$ & $\begin{array}{l}.004 \\
.000\end{array}$ \\
\hline \multicolumn{6}{|c|}{ Affect $\left(F_{\text {total }}(1,1591)=240.237 ; p<.000\right)$} \\
\hline $\begin{array}{l}\text { Health } \\
\text { (Constant) }\end{array}$ & .36 & $.13 * * *$ & $\begin{array}{l}.28 \\
2.984\end{array}$ & 15.500 & .010 \\
\hline
\end{tabular}

Note. Overall life satisfaction, and Mean score of satisfaction with three aspects of life range from 0 to 10, Affect and Subjective health ratings range from 1 ("very bad") to 5 ("very good"), with a high value indicating strong endorsement of the construct. For Marital status, 1 signifies "married" and 0 "never married."

$* * p<.01 ; * * * p<.001$ 
unemployed with an income below the 'at-riskof-poverty threshold' had lower scores in overall life satisfaction and in mean score of satisfaction with three aspects of life. A significant relationship was also found in the case of affect but its effect was small. In the group of retirees, the income effect on psychological variables was absent, and the most powerful predictor was the perception of one's own health. With the exception of the mean score of satisfaction with three aspects of life, where one percent of the variance was explained by marital status, health of retirees was the only significant predictor from among the six tested predictors. Perception of one's own health had a different significance for the psychological variables of the employed and the unemployed: while in the group of the employed, occupational health ${ }^{5}$ explained the largest percentage of variance in relation to all three variables, in the group of the unemployed this was only in the case of affect. Gender stands out among the remaining significant predictors: its effect, although small, has only been shown in the group of the unemployed - the unemployed women achieved higher scores in all three cases than the unemployed men. Finally, the significant effect of education was identified among the employees working full-

\footnotetext{
${ }^{5}$ A common definition of occupational health has been adopted by the Joint ILO/WHO Committee on Occupational Health at its first session in 1950. The definition reads: "Occupational health should aim at: the promotion and maintenance of the highest degree of physical, mental and social well-being of workers in all occupations; the prevention amongst workers of departures from health caused by their working conditions; the protection of workers in their employment from risks resulting from factors adverse to health; the placing and maintenance of the worker in an occupational environment adapted to his physiological and psychological capabilities; and, to summarize, the adaptation of work to man and of each man to his job" (Eurostat, 2013b).
}

time, higher education meant higher overall life satisfaction and affect scores.

\section{Differentiated Income Effect below the 'At- Risk-of-Poverty Threshold' in Relation to Well-Being Variables Depending on Self-De- fined Economic Status}

While earlier (e.g., Campbell, Converse, \& Rodgers, 1976) as well as more recent research (e.g., Diener et al., 1999) concludes that personal income exerts little influence on subjective wellbeing, Cummins (2000) states, in accordance with his Homeostatic Theory of Subjective WellBeing, that "there is an intimate relationship between personal wealth and SWB" (p. 133). However, at the level of a particular individual this relationship is masked by the effect of other variables, which are of internal (personality) and external nature. As examples, the author provides objective health or unemployment which, due to their persistence, may reduce SWB; therefore, in these two specific cases it is difficult to identify the specific contribution of low income. In order to reduce this uncertainty in our analysis, we included income below the 'atrisk-of-poverty threshold' as an objective variable in the first step of sequential regression, sociodemographic variables in the second and perceived health as a subjective variable in the last step. Using this procedure, it was possible to control the overlap of the income variance with the subjective variable and to identify its effect on psychological criteria of subjective nature. Of course, as Cummins (2000) states, money alone cannot have a direct impact on SWB, and since other simultaneous variables (personality and specific conditions at the time of doing the questionnaire) were not controlled in our analysis, our multiple regression does not reveal, what in fact had an impact on SWB in case of the significant effect of income below the 'at-risk-of-poverty threshold'. Nevertheless, it appears that the results obtained partly 
support Cummins' (2000) conclusion that the poor are more sensitive to their circumstances of living both as a direct and indirect consequence of poverty. The income below the 'atrisk-of-poverty threshold' was a significant predictor of low scores among employees working full-time in relation tooverall life satisfaction and among the unemployed in relation to all three well-being variables. However, hypothetical sources of low scores are likely to be different in both groups: full-time employees can be frustrated by their low income even though they have a job. Thanks to the opportunity to work they can be in touch with society, they have relative certainty regarding their housing and covering their basic needs and, even if they have a low score in total life satisfaction, their low income does not have an effect on their satisfaction with the examined areas of life and on their affect.

The situation for the unemployed is less favorable; not only does their income not usually satisfy their needs - hence the low score in satisfaction with areas of life - but due to their unemployment their expectations of the future have decreased, along with their affect score. As stated by Cummins (2000), they cannot "buy happiness to the extent that external resources allow the optimal functioning of the SWB homeostatic system" (p. 133). In the group of retirees, the assumption about the existence of the relationship of income to SWB was not supported: low income did not have a significant relationship to any of the psychological variables, i.e. overall life satisfaction, mean score of satisfaction with three aspects of life and affect. The explanation that the data come from Slovaks and thus may differ from those obtained from Western societies is implausible because similar results regarding the relationship between low income and socio-demographic characteristics to life satisfaction was identified by Smith et al. (2004) among persons over 60 years of age from three English cities. For the time being, it can be assumed that Cummins' theory is not universal and that the lack of low-income effect in this particular group of people is not a matter of its being masked by other variables; rather than that, it may be a support for the hypothesis that among Slovak retirees, low income is not a predictor of overall life satisfaction, mean score of satisfaction with three aspects of life, and affect.

\section{Different Effect Size of Subjectively Assessed Health in Relation to Well-Being Variables Depending on Self-Defined Economic Status}

In all three groups of persons, subjective health rating was a significant predictor of all three well-being variables. If in the interpretation of this result we did not take into account the volume of the effect, then a simple explanation of the universality of the effect of this variable might be that it was a predictor of the same nature as the criteria tested (subjective variables), despite the fact that the predictor was inserted in the last block in the regression. However, if we take into account the volume of the effect of subjectively assessed health, then for the two groups of people, i.e. the unemployed and the retirees, the effect of health was the highest; the result was different in the category of the unemployed. Only in relation to affect was health the strongest predictor; for overall life satisfaction and mean score of satisfaction with three aspects of life, the strongest predictor was income. The negativistic explanation that the life situation of the unemployed reduces their subjective sensitivity to the assessment of their own health and that a lack of income worsens overall life satisfaction and mean score of satisfaction with three aspects of life cannot be ruled out. An alternative explanation may also be considered: a strong dependence of the high score in affect on subjectively assessed health is related to the fact that, for this group, income or the socio-demographic factors tested 
have no significance and the only thing these people value is their subjectively assessed current state of health.

\section{A Differentiated Effect of Gender and Educa- tion Depending on Self-Defined Economic Sta- tus}

A missing effect of gender differences on well-being variables among employees and retirees supports some well-known findings (cf. Diener et al., 1999) that gender is not a SWB predictor. The fact that the effect of gender was evident in only one group of people, i.e. only among unemployed women, requires a separate analysis. It may be assumed that it results from social expectations of securing one's finances, which put higher pressure on men than on women, and that the men questioned subjectively perceived this pressure negatively. As for the positive effect of education among employees on overall life satisfaction and affect and the absence of this effect in the remaining two groups of persons, the results obtained partly correspond to the analysis by Diener et al. (1999), who explained the existence of a weakly significant relationship of education and SWB by referring to correlation of income and occupational status. The lack of relationship between education and psychological variables among retirees and the unemployed corresponds with this explanation, since neither of the two groups experience the effect of occupational status.

\section{Limitations}

The significant advantage, which rests in the quality and size of the sample, is weakened by the fact that the analysis of secondary data has been subject to several constraints. The first constraint is that the choice of analyzed variables was determined by the existing data. For example, the distribution of respondents to never married and married does not take into account those living with spouse that did not belong to any of the interviewed categories, as the unknown reviewer pointed out. The second is related to the fact that well-being variables were operationalized inadequately with regard to the dominant approach to their theoretical definition in the literature. In other words, the data analyzed were not aimed at verifying income and well-being variables and the instruments for the assessment of well-being variables were developed ad-hoc. The results obtained are, therefore, difficult to compare with other similar surveys, in which these variables are usually operationalized differently and the results of the data thus obtained provide only a rough estimate of the trends of the relations among statistically tested variables. Improving the understanding of these relationships would be possible by using the established scales with verified psychometric properties, and more accurately understanding of these relationships in specific groups would involve checking the effect of the known predictors of well-being variables, such as the effect of personality variables. Other limitations are related to how independent variables were defined and measured. The problematic use of the 'at-risk-of-poverty threshold' as an indicator of income poverty has been pointed to by authors of several studies. For example, Nygård et al. (2017, p. 684) states: "The fact that an individual or a household earns less than $50 / 60 \%$ of the median income does not necessarily mean that the individual/household is going to lack resources or suffer individual deprivation." Another source of potential imprecisions was pointed to by Angel, Heuberger, and Lamei (2017), who compared two data sources available in parallel for the same households: register-based and survey-based income data. Based on the social desirability argument, it is expected that households with low incomes tend to report a higher income than they actually have. On the other 
hand, households with a higher income are expected to make themselves 'poorer' in the interview situation. A certain understatement of income usually grows with the amount of the actual income (Večerník \& Mysíková, 2016). This also applies to incomes flowing from several sources, e.g. multiple jobs. It has thus been confirmed that while earnings tend to be skewed in income reporting by household respondents, old age or other types of pension benefits do not suffer from such distortion. As a result, the income poverty of persons in households with wage earners may be overestimated in comparison with persons living in households with retirees. Several specific issues related to EU-SILC were pointed to by Maestri (2014). Of these, we consider the fact that "Income refers to the previous year, while housing information to the current year" (p. 693) is the most serious and one which has significantly influenced the results of our analysis. Detection of psychological experiencing in the analyzed data was carried out with a considerable time delay after the assessed reference income period: the detection was held 4-5 months (April-May 2013) after the surveyed reference income period - the persons quoted their income for the previous calendar year of 2012. This time shift could have been a source of unidentified factors of reciprocal relationship of below the poverty risk and well-being variables. For example, during the assessment of subjective well-being, a person may not have had an income below the poverty risk threshold for several months, and their financial situation may have been radically improved, or even made worse. The same applies to subjective assessment of one's own health.

\section{References}

Alkire, S., et al. (2015). Multidimensional poverty measurement and analysis. Oxford: Oxford University Press. https://doi.org/10.1093/acprof:oso/ 9780199689491.001 .0001
Angel, S., Heuberger, R., \& Lamei, N. (2017). Differences between household income from surveys and registers and how these affect the poverty headcount: Evidence from the Austrian SILC. Social Indicators Research, https://doi.org/10.1007/s11205-0171672-7

Annoni, P., \& Weziak-Bialowolska, D. (2016) A measure to target antipoverty policies in the European Union regions. Applied Research in Quality of Life, 11(1), 181-207. https://doi.org/10.1007/s11482014-9361-z

Arndt, Ch., \& Volkert, J. (2007). A capability approach for official German poverty and wealth reports: Conceptual background and first empirical results, IAW Diskussionspapiere, 27.

Cummins, R. A. (2000). Personal income and subjective well-being: A review. Journal of Happiness Studies, 1(2), 133-158. https://doi.org/10.1023/A: 1010079728426

De Smedt, M. (2013). Measuring subjective issues of well-being and quality of life in the European statistical system. Social Indicators Research, 114(1), 153-167. https://doi.org/10.1007/s11205-0130389-5

Diener, E. (2000). Subjective well-being. The science of happiness and a proposal for a national index. American Psychologist, 55(1), 34-43. https:// psycnet.apa.org/doi/10.1037/0003-066X.55.1.34

Diener, E., Emmons, R. A., Larsen, R. J., \& Griffin, S. (1985). The satisfaction with life scale. Journal of Personality Assessment, 49(1), 71-75. https:// psycnet.apa.org/doi/10.1207/s15327752jpa4901_ 13

Diener, E., Sandvik, E., Seidlitz, L., \& Diener, M. (1993). The relationship between income and subjective well-being: Relative or absolute? Social Indicators Research, 28(3), 195-223. https://doi.org/ 10.1007/BF01079018

Diener, E., \& Diener, M. (1995). Cross cultural correlates of life satisfaction and self-esteem. Journal of Personality and Social Psychology, 68(4), 653-663. https://doi.org/10.1007/978-90-481-2352-0 4

Diener, E., Suh, E. M., Lucas, R. E., \& Smith, H. L. (1999). Subjective well-being: Three decades of progress. Psychological Bulletin, 125(2), 276-302. https://psycnet.apa.org/doi/10.1037/0033-2909. 125.2 .276

Diener, E., \& Biswas-Diener, R. (2002). Will money increase subjective well-being? Social Indicators Research, 57(2), 119-169. https://doi.org/10.1023/ A:1014411319119

Eurostat (2010). Eurostat statistical book "Income and living conditions in Europe”. Luxembourg: Office for Official Publications of the European Communities. https://doi.org/10.2785/53320 
Eurostat (2013a). Methodological guidelines and description of EU-SILC target variables. 2014 operation (Version September 2013).

Eurostat (2013b). Guide to statistics in European Commission development co-operation - 2013 Edition. https:/ec.europa.eu/eurostat/documents/3859598/ 5926413/KS-RA-13-002-EN.PDF/69c1a2d4-335e4579-bc7b-42db1c691ae2

Eurostat (2018). Statistics explained (Version August 2018). https://ec.europa.eu/eurostat/statistics-explained/index.php?title $=$ Glossary:Equivalised disposable_income

Haushofer, J. (2013). The psychology of poverty: Evidence from 43 countries. MIT Working Paper. Cambridge, MA: MIT.

Laderchi, C. R., Saith, R., \& Stewart, F. (2003). Does it matter that we do not agree on the definition of poverty? A comparison of four approaches. Oxford Development Studies, 31(3), 243-274. https:// doi.org/10.1080/1360081032000111698

Leech, N. L., Barrett, K. C., \& Morgan, G. A. (2015). IBM SPSS for intermediate statistics. Use and interpretation. New York and London: Routledge. https:/ /doi.org/10.4324/9780203122778

Lucas, R. E., Diener, E., Grob, A., Suh, E. M., \& Shao, L. (2000). Cross-cultural evidence for the fundamental features of extraversion. Journal of Personality and Social Psychology, 79(3), 452-468. https:/ /psycnet.apa.org/doi/1 0.1037/0022-3514.79.3.452

Mack, A. (2016). Data handling in EU-SILC. (Gesis Papers 2016/10). Leibniz, Institut für Sozialwissenschaften.

Maestri, V. (2015). A measure of income poverty including housing: Benefits and limitations for policy making. Social Indicators Research, 121(3), 675696. https://doi.org/10.1007/s1 1205-014-0657-z

Ngamaba, K. H., Panagioti, M., \& Armitage, Ch. J. (2017). Income inequality and subjective well-being: A systematic review and meta-analysis. Quality of Life Research, 27(3), 577-596. https://doi.org/ 10.1007/s1 1136-017-1719-x

Norton, A., et al. (2001). A rough guide to PPAs: Participatory Poverty Assessment: An introduction to theory and practice. Overseas Development Institute.

Nygård, M., Härtull, C., Wentjärvi, A., \& Jungerstam, S. (2017). Poverty and old age in Scandinavia: A problem of gendered injustice? Evidence from the 2010 GERDA Survey in Finland and Sweden. Social Indicators Research, 132(2), 681-698. https:// doi.org/10.1007/s11205-016-1313-6

Senik, C. (2008). Ambition and jealousy: Income interactions in the "Old" Europe versus the "New" Europe and the United States. Economica, 75(299), 495-513. https://doi.org/10.1111/j.1468-0335. 2007.00629.x

Smith, A. E., Sim, J., Scharf, T., \& Phillipson, Ch. (2004). Determinants of quality of life amongst older people in deprived neighbourhoods. Aging and Society, 24(5), 793-814. https://doi.org/10.1017/ S0144686X04002569

Tabachnick, B. G., \& Fidell, L. S. (2013). Using multivariate statistics. Pearson Education, Inc.

Večerník, J., \& Mysíková, M. (2016). Poverty in Czech Republic. A critical look at EU indicators. Prague: The Institute of Sociology of the Czech Academy of Sciences.

Vlačuha, R., \& Kováčová, Y. (2015). EU SILC 2014. Indikátory chudoby a sociálneho vylúčenia. [EU SILC 2014. Indicators of poverty and social exclusion]. Bratislava: Statistical Office of the Slovak Republic.

Warner, R. M. (2008). Applied statistics. Los Angeles: Sage.

Yu, Z., \& Wang, F. (2017). Income inequality and happiness: An inverted U-shaped curve. Frontiers in Psychology, 8(2052). https://doi.org/10.3389/fpsyg. 2017.02052 